\title{
Emergência de Respostas de Seguir InstruÇão e de Tato-Intraverbal APÓs INSTRUÇÁo COM MÚlTiPLOS EXEMPLARES ${ }^{1,2}$
}

\author{
EMERGENCE OF RULE FOLLOWING aNd TACT-INTRAVERBAL RESPONSES AFTER \\ MULTIPLE EXEMPLAR INSTRUCTION
}

\author{
Elaine de Carvalho SILVA ${ }^{3}$ \\ Nassim Chamel ELIAS ${ }^{4}$
}

\begin{abstract}
RESUMO: O objetivo deste estudo foi verificar os efeitos do ensino com Instrução com Múltiplos Exemplares (Multiple Exemplar Instruction - MEI), envolvendo, em cada tentativa, a resposta de seguir uma instrução tato-intraverbal para uma relação espacial (por exemplo, esquerda) na emergência de novas respostas e para uma relação espacial não ensinada diretamente (por exemplo, direita) para partes do corpo (braço, orelha, mão, perna). Adicionalmente, foi testada a generalização por meio de objetos que não foram utilizados no ensino com MEI. Os participantes foram quatro crianças e adolescentes diagnosticados com Transtorno do Espectro do Autismo (TEA) e deficiência intelectual, de sete a 14 anos. A sequência do procedimento foi: testes de seguir instrução e de tato-intraverbal em linha de base; ensino com $M E I$ para uma relação espacial; teste final de seguir instrução e de tato-intraverbal para a relação espacial não ensinada diretamente; teste de generalização. Foi utilizado o delineamento de múltiplas sondagens acoplado ao delineamento de linha de base múltipla entre os participantes. Os resultados sugerem que o ensino com $M E I$ foi suficiente para a emergência das respostas não ensinadas diretamente e de generalização. Pôde-se inferir que o procedimento foi eficaz e eficiente, pois gerou a emergência de respostas não ensinadas diretamente e a aprendizagem se deu em poucos blocos.
\end{abstract}

PALAVRAS-CHAVE: Linguagem. Instrução com Múltiplos Exemplares. Autismo.

\begin{abstract}
The objective of this study was to verify the effects of teaching with Multiple Exemplar Instruction (MEI) involving, in each trial, the response of following a tact-intraverbal instruction to a spatial relation (for example, left) in the emergence of new responses and for the spatial relation not directly taught (for example, right) for body parts (arm, ear, hand, leg). Additionally, generalization was tested by means of objects that were not used in teaching. Participants were four children and adolescents diagnosed with Autism Spectrum Disorder (ASD) and intellectual disability, aged seven to fourteen. The sequence of the procedure was: tests of rule following and tact-intraverbal in baseline; teaching with MEI for a spatial relation; final test of rule following and tact-intraverbal for the spatial relation not directly taught; generalization test. Multiple probes design coupled with multiple baseline across participants design was used. The results suggest that teaching with MEI was sufficient for the emergence of responses not directly taught and generalization. It could be inferred that the procedure was effective and efficient, as it generated the emergence of responses not directly taught and the learning took place in a few blocks.
\end{abstract}

KEYWORDS: Language. Multiple Exemplar Instruction. Autism.

\section{INTRODUÇÁo}

A manifestação dos sintomas centrais do Transtorno do Espectro do Autismo (TEA), como déficits na comunicação, na interação social e nos interesses restritos, pode variar ampla-

\footnotetext{
${ }^{1}$ https://doi.org/10.1590/1980-54702021v27e0228

${ }^{2}$ Os autores agradecem à Coordenação de Aperfeiçoamento de Pessoal de Nível Superior (CAPES) pelo apoio contínuo geral à pesquisa (PROEX 23038.005155 / 2017-67) e pela bolsa de Doutorado à primeira autora. Esta pesquisa foi conduzida como parte da tese de Doutorado da primeira autora junto ao Programa de Pós-Graduação em Educação Especial da Universidade Federal de São Carlos (UFSCar).

${ }^{3}$ Doutora pelo Programa de Pós-Graduação em Educação Especial. Universidade Federal de São Carlos (UFSCar). São Carlos / São Paulo / Brasil. E-mail: elacarvalhos@gmail.com. ORCID: https://orcid.org/0000-0003-1016-9718

${ }^{4}$ Doutor em Educação Especial e Professor do Departamento de Psicologia da Universidade Federal de São Carlos (UFSCar). São Carlos / São Paulo / Brasil. E-mail: nassim@ufscar.br. ORCID: https://orcid.org/0000-0003-4197-623X
} 
mente (American Psychiatric Association [APA], 2013), podendo, por exemplo, apresentar linguagem receptiva, mas não expressiva e vice-versa, ou, ainda, não apresentar forma de linguagem e estar frequentemente relacionada às habilidades cognitivas e estruturais da linguagem.

Nesse sentido, Haebig e Sterling (2017) estudaram o perfil do vocabulário receptivo-expressivo de dois grupos de indivíduos com TEA com idades de nove a 16 anos e com atrasos significativos no desenvolvimento cognitivo. Um grupo era composto por indivíduos com TEA e idiopatia e o outro com TEA e Síndrome do X frágil. Os participantes foram expostos a avaliaçóes cognitivas e de linguagem e a avaliaçóes sobre a gravidade do TEA. Os resultados indicaram que o grupo com TEA e Síndrome do X frágil não apresentaram o mesmo perfil receptivo-expressivo atípico que o grupo com TEA e idiopatia. Os autores afirmam que, embora surjam falhas significativas no vocabulário receptivo em ambos os grupos, a maioria dos participantes não apresentou esse perfil e esclarecem que não foram identificados preditores claros de diferenças no vocabulário expressivo-receptivo para nenhum dos grupos. Entretanto, o Quociente de Inteligência (QI) não-verbal e o vocabulário expressivo estavam positivamente associados ao conhecimento do vocabulário receptivo nos dois grupos. Adicionalmente, o vocabulário receptivo previa o vocabulário expressivo, mas o QI não-verbal era apenas um preditor marginalmente significativo de vocabulário expressivo. Por fim, os autores sugerem que, por meio da comparação dos dois grupos, o estudo destacou áreas de sobreposição e divergência em perfis de linguagem dentro do guarda-chuva mais amplo do TEA.

A literatura comportamental vem apresentando recomendaçóes sobre o ensino de linguagem receptiva e expressiva para crianças com TEA. Contreras et al. (2020) fizeram uma revisão de pesquisas sobre a eficiência de instruçóes para aquisição de habilidades de falante (linguagem expressiva) e de ouvinte (linguagem receptiva). Apesar dos resultados indicarem maior eficácia para instruçóes de falante na emergência de repertórios de ouvinte do que o contrário, os autores sugerem que náo haja descarte do treinamento de repertórios de ouvinte, pois nem sempre ocorrerá a emergência de respostas de ouvinte não ensinadas diretamente, o que necessita, portanto, testar o surgimento de respostas de ouvinte após o treino de respostas de falante. Vale lembrar uma das recomendaçóes de Petursdottir e Carr (2011), que é comparar o ensino simultâneo ou misto de falante e ouvinte com estratégias alternativas.

Nesse cenário, Sprinkle e Miguel (2012) objetivaram avaliar e comparar o uso de discriminação condicional (resposta de ouvinte) e treinamento de resposta textual e de tato (falante) no estabelecimento de classes de estímulos equivalentes, contendo nomes ditados, resposta de tato ou textual, figuras e palavras impressas. Para isso, utilizaram um delineamento de tratamentos alternados com um conjunto de estímulos para cada condição de treinamento de falante e de ouvinte. Esses treinamentos foram implementados simultaneamente. Os participantes foram quatro crianças (com idades entre cinco e sete anos), diagnosticadas com TEA. As crianças foram ensinadas a selecionar figuras e palavras impressas na presença de seus nomes ditados e a emitir a resposta de tato ou textual na presença de uma imagem ou palavra impressa. Também foram aplicados pré e pós-testes para medir relaçóes emergentes. Segundo Sprinkle e Miguel (2012), os resultados indicaram que "tanto o treino do falante quanto o do ouvinte resultaram na formação de classes de estímulos equivalentes para todos os participantes” (p. 115). 
Kobari-Wright e Miguel (2014) avaliaram os efeitos do treino de ouvinte para o surgimento da categorização de figuras e de comportamento de tato. Quatro crianças com TEA (três crianças com quatro anos e uma com cinco anos de idade) foram ensinadas a selecionar figuras de acordo com os nomes de categorias ditadas. A avaliação foi feita para verificar se as crianças poderiam combinar e aplicar tato às fotos por categoria. $\mathrm{O}$ delineamento empregado foi de linha de base múltipla não simultânea entre participantes. De acordo com os autores, após o treinamento, três participantes categorizaram todas as fotos (durante os testes) e um participante falhou em ambos os testes, porém, após o treino direto de tato, esse participante apresentou respostas de categorização. Para Kobari-Wright e Miguel (2014), esses resultados sugerem que o treinamento de resposta de ouvinte pode ser uma maneira eficiente de produzir comportamento de falante e categorização em crianças com TEA, mas é importante estabelecer a "nomeação" (Horne \& Lowe, 1996) antes de a categorização emergir. Kobari-Wright e Miguel (2014) afirmam também que, na ausência de nomes, as categorias podem ser estabelecidas com base em outros recursos ou em outras funçóes em vez de habilidades verbais. Nesse contexto, os autores sugerem outras pesquisas que repliquem esses resultados utilizando um delineamento experimental mais conservador e com participantes que apresentem diferentes repertórios verbais. Além disso, os pesquisadores sugerem que os estudos devem determinar quem se beneficiaria de qual tipo de treinamento - ouvinte ou falante.

Um dos pontos centrais da Teoria da Nomeação de Horne e Lowe (1996) é a ênfase no comportamento do ouvinte e a conceituação do indivíduo como falante-ouvinte dentro da mesma pele, pois, dessa forma, o indivíduo passa a ser verdadeiramente verbal quando ocorre a junção das funçôes de falante e de ouvinte. Para Horne e Lowe (1996), a nomeação constitui a unidade comportamental básica da linguagem e pode ser definida como uma relaçáo bidirecional entre um componente do falante (por exemplo, o tato ou o intraverbal) e um do ouvinte (por exemplo, discriminação condicional ou seguir instruções). Ela ocorre quando apenas um desses dois componentes é suficiente para estabelecer ambas as relaçóes (Horne \& Lowe, 1996). Dessa forma, uma vez que o indivíduo tenha aprendido várias relaçóes de nomeação, o ensino de relaçóes de ouvinte pode ser suficiente para a emergência de relaçóes de falante e vice-versa.

Para Fiorile e Greer (2007), assim como para Elias e Arantes (2019), a aquisição da nomeação é fundamental para o desenvolvimento da linguagem. Os autores ressaltam que muitas crianças com TEA ou atrasos de linguagem não adquirirem esse repertório. Nesse seguimento, Fiorile e Greer (2007) fizeram um experimento para testar condiçóes e estímulos que poderiam levar os participantes da pesquisa ao repertório de nomeação. Os participantes foram quatro crianças com TEA e com atraso de linguagem sem repertório ecoico nem tato. Inicialmente, foram ensinadas respostas de tato, o que não resultou no repertório de nomeação. Em seguida, foram ensinados repertórios de falante e de ouvinte utilizando a Instrução com Múltiplos Exemplares (MEI, do inglês Multiple Exemplar Instruction) para um subconjunto de estímulos (conjunto de ensino), resultando em componentes não ensinados de nomeação e na capacidade de adquirir nomeação após aprender tatos para conjuntos subsequentes de estímulos. Fiorile e Greer (2007) sugeriram que a $M E I$ é um procedimento eficaz para estabelecer a nomeação. Portanto, ensinar respostas de tato e de ouvinte, para um determinado conjunto de estímulos, foi suficiente para que o ensino somente do tato para outro conjunto de estímulos produzisse as respostas de ouvinte sem ensino direto, constituindo a característica bidirecional da nomeação. 
O ensino com $M E I$ consiste na apresentação rotativa de tarefas que envolvem habilidades de falante e de ouvinte. Segundo Cooper et al. (2007), a MEI é uma forma de instrução que: a) proporciona a prática com uma variedade de topografias de resposta (os múltiplos exemplares) que ajudam a garantir a aquisição de formas desejadas dessa resposta; b) promove a generalização da resposta para topografias não ensinadas diretamente; e c) pode incorporar variaçóes tanto de respostas como de estímulos.

Em 2007, Greer et al. também conduziram um estudo com o objetivo de comparar os efeitos de $M E I$ com os efeitos de Instrução com Exemplar Único (SEI, do inglês Singular Exemplar Instruction) na emergência de respostas de falante e de ouvinte (nomeação) não ensinadas diretamente. A $M E I$ consistia em expor os participantes a uma rotação entre respostas de ouvinte (emparelhamento e escolha, de acordo com o modelo) e respostas de falante (tato e intraverbal), uma seguida da outra, repetindo essa sequência para estímulos distintos. Já a $S E I$ consistia em expor os participantes às mesmas topografias de respostas da $M E I$, mas cada topografia era ensinada em sessóes separadas, sem a rotação (por exemplo, em uma sessão eram ensinadas somente respostas de emparelhamento; em outra sessão, somente escolha de acordo com o modelo; e assim por diante). Os participantes foram oito crianças pré-escolares (de 3 a 5 anos) com atraso de linguagem e sem domínio de nomeação, divididas em dois grupos. Um grupo foi ensinado com SEI e outro com $M E I$. Os resultados indicaram que as respostas de nomeação emergiram somente para o grupo que recebeu o ensino com $M E I$. Posteriormente, o grupo ensinado com SEI também recebeu o ensino com $M E I$ e as respostas de nomeação emergiram. Assim sendo, nesse estudo, Greer et al. (2007) afirmam que somente o ensino com MEI foi eficaz para estabelecer a nomeação para crianças que não tinham esta capacidade.

Nos estudos citados anteriormente, há o ensino direto de respostas de falante e de ouvinte para determinados conjuntos de estímulos para, em seguida, ensinar um desses repertórios (por exemplo, falante), para um novo conjunto de estímulos, e testar o outro repertório (por exemplo, ouvinte), para esse mesmo conjunto. Entretanto, nenhum desses estudos investigou o ensino de repertórios de falante e de ouvinte para determinados conjuntos nem testou a emergência de novas respostas de falante e de ouvinte para novos conjuntos, sem que nenhum ensino direto tivesse sido introduzido (por exemplo, ensinar diretamente a levantar o braço direito e a responder "direito" à pergunta "Que braço é esse?" e testar se o participante faz o movimento correto quando é solicitado a levantar o braço esquerdo e se responde "esquerdo" à pergunta "Que braço é esse?").

No presente estudo, foram utilizados repertórios de ouvinte de seguir instrução (por exemplo, "Levante o braço direito") e repertórios de falante como tato-intraverbal (por exemplo, após a pesquisadora apontar uma parte do corpo do participante, era feita a pergunta "De que lado está esse braço?”); a parte do corpo é o estímulo não-verbal que controla a resposta de tato em conjunto com a pergunta como estímulo verbal que controla a resposta intraverbal. Segundo Skinner (1957), o tato é uma resposta verbal controlada por estímulos não-verbais, como objetos ou eventos ou por suas propriedades, e é mantida por reforçadores generalizados; já o intraverbal é uma resposta verbal sob controle de um estímulo verbal - como responder a uma pergunta ou engajar-se em uma conversa, não havendo correspondência ponto-a-ponto entre estímulo e resposta - e é mantida por reforçadores generalizados. 
Desse modo, o objetivo deste estudo foi verificar os efeitos do ensino com $M E I$, envolvendo, em cada tentativa, os dois componentes da nomeação (resposta de seguir instrução e, em seguida, resposta de tato-intraverbal) para uma relação espacial (por exemplo, esquerda) na emergência de novas respostas de seguir instrução e de tato-intraverbal para a relação espacial não ensinada diretamente (por exemplo, direita) para as partes do corpo (braço, orelha, máo e perna). Foi realizado também um teste de generalização com objetos que não foram utilizados na fase de ensino.

\section{Método}

A seguir, serão apresentados os participantes, o local, os equipamentos e materiais, os procedimentos bem como o delineamento e os cuidados para garantir confiabilidade dos dados desta pesquisa.

\subsection{Participantes}

Os participantes foram duas crianças (P1 e P2) e dois adolescentes (P3 e P4) diagnosticados com TEA e deficiência intelectual, na faixa etária de sete a 14 anos. Para participar do estudo, o participante precisaria apresentar $80 \%$ de respostas corretas no teste de repertório de imitação motora e vocal e no máximo de $40 \%$ de respostas corretas no pré-teste das relaçóes do estudo. $\mathrm{O}$ critério de exclusão seria não estar dentro do espectro, obter escores baixos nos testes de imitação motora e vocal ou apresentar alguma limitação sensorial, como cegueira e surdez. Os quatro participantes já apresentavam respostas vocais ecoicas, conforme identificado pelo teste de imitação vocal como critério de inclusão.

As informações sobre diagnóstico, idade, uso de medicamentos, comportamentos e nível de aprendizagem foram disponibilizadas pela instituição especializada que os participantes frequentavam. Ao longo do procedimento, foi possível observar que, além do comportamento ecoico que foi testado diretamente, os participantes apresentavam mandos, tatos e intraverbais. Somente P2 apresentava o comportamento textual, mas com dificuldades para a escrita. Já P1, com dez anos de idade, não estava alfabetizado (não apresentava repertórios de leitura e escrita), mas respondeu rapidamente às tentativas.

P2, com sete anos de idade, estava alfabetizado (com repertório de leitura, porém com dificuldade motora que prejudicava sua escrita), reconhecia palavras simples em inglês e nomeava figuras (tato), expressando, de forma vocal, corretamente as palavras em inglês e português. Por apresentar Transtorno de Déficit de Atenção e Hiperatividade (TDAH), P2 fazia uso de medicação, a qual estava sendo substituída (pelo seu médico) durante o período de participação na coleta de dados desta pesquisa. Essa questão resultou em alguns comportamentos inadequados em algumas sessóes, sendo uma delas interrompida devido à agitação e à impaciência do participante (a pesquisadora perguntou ao participante se ele queria interromper a sessão e ele concordou). A sessão foi interrompida antes do início do ensino, por isso não foi contabilizada. Nas demais sessóes, o participante respondeu a todas as tentativas.

P3, de 14 anos de idade, iniciante no processo de alfabetização (começou o reconhecimento das vogais), tinha dificuldades na pronúncia de palavras, o que tornava sua fala pouco 
compreensível. Além disso, apresentava comportamentos de agressividade com os demais colegas em sala de aula; esses comportamentos, porém, não ocorreram durante as sessóes com a pesquisadora e $\mathrm{P} 3$ respondeu rapidamente às tentativas.

P4, de 14 anos de idade, estava em processo inicial de alfabetização, compreendia instruçóes e apresentava resposta vocal compreensível. O participante apresentou comportamento de interação com a pesquisadora respondendo adequadamente às tentativas.

Antes do início do recrutamento dos participantes e da coleta de dados, o projeto foi submetido e aprovado por um Comitê de Ética em Pesquisas em Seres Humanos. Em seguida, a pesquisa, com seus objetivos e procedimentos, foi apresentada aos pais ou responsáveis, para que, caso concordassem com a participação de seus filhos, fizessem a leitura e a assinatura do Termo de Compromisso Livre e Esclarecido para efetivar a autorização.

\subsection{LOCAL}

A coleta de dados desta pesquisa, para os quatro participantes, foi realizada em uma sala (para P1, P2 e P3) ou no parque (para P4) da instituição especializada que eles frequentavam. A instituição atendia a crianças com diagnóstico de TEA com ou sem outras comorbidades. A sala, com tamanho de 2,5 metros por 2,5 metros, tinha uma porta de entrada e uma janela ampla que possibilitava iluminação natural ao ambiente, com duas mesas, duas cadeiras, um armário (contendo jogos, brinquedos educativos e materiais de pintura) e uma estante na parede. No início do período da pesquisa e depois de algumas faltas de P4, a pesquisadora foi informada pela professora que o participante estava se recusando a entrar em sala de aula ou em qualquer sala da instituição e que esse comportamento se iniciou devido à mudança de medicação. Com isso, a pesquisadora conduziu a coleta com P4 no parque de areia da instituição em concordância com o participante e com a equipe que o atendia. $\mathrm{O}$ espaço de areia tinha por volta de sete metros, composto por uma gangorra, dois balanços e um escorregador. Esse espaço, que contorna toda a instituição, era rodeado por árvores, tinha um pequeno lago, um quiosque aberto com mesas e cadeiras de cimento e um local fechado para guardar materiais de jardinagem.

\subsection{EQUiPAMENTOS E MATERIAIS}

Foi utilizado um celular (Samsung Galaxy A5/2017 modelo SM-A520F) para filmar as sessões e um suporte para celular. Brinquedos como quebra-cabeça, boneca, carrinho, caminhão, jogo da memória e slime (geleca) foram utilizados como consequência para respostas corretas. Outros materiais foram utilizados com todos os participantes: dois cartóes, dois carrinhos, duas cadeiras e uma mesa (para testes de generalização). Protocolos de registro, lápis e canetas foram utilizados pela pesquisadora para registro das tentativas de ensino e de teste.

\subsection{Procedimento}

Sonda de Imitação Motora. Essa fase foi conduzida para garantir que os participantes apresentassem imitação motora, utilizada como dica durante as sessóes de ensino. O repertório de imitação motora foi testado individualmente, por meio de tentativas discretas que iniciaram 
com a instrução verbal "Faça isso" e com um movimento executado pela experimentadora (tocar o nariz, bater palmas, levantar os braços, tocar as orelhas, sentar-se na cadeira, levantar uma perna e a outra alternando, olhar para um lado e para outro virando só a cabeça, colocar as mãos nos joelhos, levantar-se da cadeira, andar em volta da cadeira). Respostas foram consideradas corretas quando o participante imitou a ação realizada pela experimentadora. Outras respostas foram consideradas incorretas. As respostas corretas foram seguidas de elogio verbal descritivo (por exemplo, "Muito bem, você tocou o nariz!"); respostas incorretas foram seguidas de intervalo intertentativas de 5 segundos e da apresentação da próxima tentativa. Essa sonda foi composta por um único bloco com 10 tentativas.

Sonda de Imitação Vocal. Essa fase foi conduzida para garantir que os participantes apresentassem imitação vocal (ecoico), utilizada como dica durante as sessóes de ensino. $\mathrm{O}$ repertório de imitação vocal foi testado individualmente, por meio de tentativas discretas que iniciaram com a instrução verbal "Diga", seguida de palavras ou pseudopalavras distintas, com duas ou três sílabas (cano, vala, pora, bero, difo, papiro, mesada, pintura, benego, vicajo). Respostas foram consideradas corretas quando o participante repetia a palavra dita pela experimentadora. Outras respostas foram consideradas incorretas. As respostas corretas foram seguidas de elogio verbal descritivo (por exemplo, "Muito bem, você disse cano!"); respostas incorretas foram seguidas de intervalo intertentativas de 5 segundos e da apresentação da próxima tentativa. Essa sonda foi composta por um único bloco com 10 tentativas.

Avaliação de Preferência. Professoras e equipe de atendimento (fonoaudióloga e psicóloga) fizeram a indicação de brinquedos considerados de preferência dos participantes. Os itens indicados foram apresentados aos participantes antes de cada sessão experimental para avaliação de preferência com múltiplos estímulos sem reposição (Carr et al., 2000). Os itens de maior preferência foram utilizados como consequência para respostas corretas nas fases de ensino. Ao início de cada sessão, os itens foram apresentados ao participante sobre a mesa, seguidos da instrução "Escolha um". Após a escolha, o participante teve acesso ao item escolhido por 15 segundos. Caso houvesse o pedido de outro brinquedo ou a perda de interesse do participante pelo item escolhido durante a sessão, uma nova oportunidade de escolha era apresentada, com todos os itens, exceto aqueles já escolhidos, em posições distintas a cada avaliação.

Teste de Repertório de Seguir Instrução. Cada tentativa iniciou com o participante em frente à experimentadora. Após a obtenção da atenção do participante, a experimentadora forneceu uma instrução identificando uma ação, um objeto ou uma parte do corpo e sua relação espacial (por exemplo, "Levante o braço direito"). Respostas foram consideradas corretas quando o participante realizou a ação solicitada em até 10 segundos. Outras respostas foram consideradas incorretas. Não houve consequências diferenciais para respostas corretas e incorretas. Foram apresentadas as seguintes tentativas: "Levante o braço esquerdo", "Toque a orelha direita”, "Levante a perna direita”, "Mostre a mão esquerda”, "Toque a orelha esquerda”, "Levante o braço direito", "Levante a perna esquerda", "Mostre a mão direita", "Sente na cadeira da esquerda", "Pegue o carrinho da esquerda", "Sente na cadeira da direita", "Levante o cartão da esquerda", "Pegue o carrinho da direita", "Levante o cartão da direita”. Essas instruçôes foram apresentadas randomicamente, de maneira que a mesma parte do corpo ou do objeto e a relação espacial não fossem apresentadas em tentativas consecutivas. 
Teste de Repertório de Tato-Intraverbal. Cada tentativa iniciou com o participante em frente à experimentadora. Após a obtenção da atenção do participante, a experimentadora apresentou uma pergunta que tivesse como possíveis respostas "esquerda" ou "direita" e, ao mesmo tempo, apontou para uma parte do corpo do participante ou para um material. Respostas foram consideradas corretas quando o participante disse a relação espacial correta em até 10 segundos. Outras respostas foram consideradas incorretas. Não houve consequências diferenciais para respostas corretas e incorretas. Foram apresentadas as seguintes perguntas: "De que lado está este braço?", "De que lado está esta perna?”, "De que lado está esta orelha?", "De que lado está esta mão?”, "De que lado está este carrinho?”, "De que lado está esta cadeira?”, "De que lado está este cartão?”. Essas instruçóes foram apresentadas randomicamente, de maneira que a mesma parte do corpo ou do objeto e a relação espacial não fossem apresentadas em tentativas consecutivas.

Ensino com MEI. Cada participante foi ensinado, individualmente, a executar uma ação com uma parte do corpo de acordo com uma relação espacial (direita ou esquerda) solicitada pela experimentadora e, imediatamente após a resposta motora, a responder de forma vocal ao ser questionado sobre qual o lado do corpo que executou a ação. Cada tentativa de ensino iniciou com o participante em frente à experimentadora. Após obter a atenção do participante (ao falar seu nome e, quando necessário, movimentar a mão na frente de seus olhos), a experimentadora forneceu uma instrução (por exemplo, "Levante o braço direito"). Respostas foram consideradas corretas quando o participante realizou a ação solicitada em até 10 segundos e foram seguidas de elogio verbal e da segunda instrução “Muito bem! De que lado está este braço?”. Quando as duas respostas estavam corretas, era feita a entrega do item de maior preferência. Respostas incorretas implicaram fornecimento de dicas de imitação na tentativa seguinte, por exemplo, quando a instrução foi "Levante o braço direito", a experimentadora apresentava a instrução e, simultaneamente, realizava a ação para que o participante pudesse imitá-la. Se a dica de imitação não fosse suficiente, dicas gestuais (apontar a parte do corpo) ou físicas (auxiliar fisicamente o participante a realizar a ação, como pegar o braço do participante com a mão e levantá-lo) foram introduzidas. As dicas foram esvanecidas de acordo com o desempenho do participante.

Quanto às respostas vocais (intraverbais), se estas estivessem incorretas, a experimentadora falava a resposta para que o participante repetisse (dica ecoica). Por exemplo, quando a pergunta era "De que lado está este braço?" e a resposta correta era "esquerdo", a resposta era dada para que o participante pudesse fazer a imitação vocal. Essas dicas foram esvanecidas em três tentativas consecutivas (na primeira tentativa foi dito "esquerda"; na segunda, "esquer..."; e na terceira, "es...”). Depois, foi realizado o mesmo procedimento para outra instrução (por exemplo, "Levante a perna direita") seguida da pergunta correspondente. Foram utilizadas as mesmas instruçóes e perguntas dos testes de repertório receptivo e expressivo, descritos anteriormente, para as partes do corpo (braços, orelhas, mãos e pernas); instruções e perguntas que envolveram objetos (cadeira, carrinhos e cartóes) foram utilizadas somente nos testes posteriores de generalização. Cada bloco foi composto por até 12 tentativas (instrução e pergunta compunham uma tentativa), em que duas instruçôes seguidas das perguntas correspondentes foram apresentadas em seis tentativas cada uma, de forma intercalada, ou até que o participante alcançasse o critério. Após respostas corretas, havia um intervalo intertentativas, em que o participante tinha acesso ao item de maior preferência por 20 segundos. O critério de aprendizagem para seguir para as fases subsequentes (ensino de duas novas açóes com as perguntas) 
foi a apresentação de uma resposta correta para duas instruçóes e duas perguntas de forma independente (sem dica).

Sequência do Procedimento. Após os participantes terem sido expostos aos testes de seguir instrução e de tato-intraverbal em linha de base, foram divididos em dois grupos (Grupo 1 e Grupo 2) para o ensino com MEI. Considerando que o desempenho dos participantes em linha de base foi muito semelhante, cada grupo foi composto por um participante mais novo (P1 ou P2) e um participante mais velho (P3 ou P4). Para o Grupo 1 (P1 e P3), foram ensinados repertórios envolvendo instruçóes e respostas para o lado direito; para o Grupo 2 (P2 e P4), foram ensinados repertórios para o lado esquerdo. Cada sessão foi iniciada com a reapresentação dos testes de seguir instrução e de tato-intraverbal para o lado contrário ao do ensino (ensino para o lado direito, testes para o lado esquerdo e vice-versa). Em seguida, duas novas açóes foram ensinadas até obterem o critério de aprendizagem estabelecido. Após o alcance de critério para todas as instruçôes e perguntas relacionadas às partes do corpo, foi apresentado um teste final envolvendo todas as tentativas apresentadas nos testes de seguir instrução e de tato-intraverbal (partes do corpo e objetos). Os testes que abrangeram objetos foram considerados como testes de generalização.

\subsection{Delineamento}

Foi utilizado um delineamento de múltiplas sondagens (Gast \& Ledford, 2014), no qual a coleta de dados é feita de forma intermitente, intercalando blocos de teste com blocos de ensino. Mais especificamente, antes de cada sessão de ensino um teste foi aplicado. Adicionalmente, foi feito o delineamento de linha de base múltipla entre participantes (Cozby, 2014) pelos testes de seguir instrução e de tato-intraverbal com pré e pós-teste, tendo o sujeito como seu próprio controle para os mesmos repertórios.

\subsection{CUIDADOS PARA GARANTIR CONFIABILIDADE DOS DADOS}

Todas as sessóes foram filmadas para registro dos dados pela experimentadora e por um segundo observador para cálculos de fidedignidade. A concordância foi calculada para 30\% das sessóes, dividindo-se o número de concordâncias pelo número de concordâncias mais o número de discordâncias e multiplicado por 100. Houve concordância de $100 \%$. Além disso, foi verificada também a consistência procedural, em que o comportamento da experimentadora, na aplicação correta do procedimento, foi avaliado por um observador que preencheu uma ficha com o registro desses comportamentos para $40 \%$ das filmagens. A ficha era preenchida para cada tentativa, indicando se houve apresentação correta da instrução e da pergunta, apresentação correta dos materiais, ausência de dicas não programadas e intervalo intertentativas. Os resultados indicaram que a experimentadora realizou $90 \%$ das tentativas de acordo com o procedimento. De acordo com Kazdin (1982), se o índice de concordância entre observadores for acima de $70 \%$, os dados obtidos podem ser considerados confiáveis.

\section{Resultados E discussáo}

Em relação aos testes de imitação motora e vocal, todos os participantes apresentaram $100 \%$ de respostas corretas na primeira aplicação. Isso indica que os participantes já possuíam repertório de imitação motora e de respostas ecoicas e respondiam sob controle de instrução verbal. 
A Figura 1 que segue apresenta o desempenho dos participantes nos blocos de ensino ao longo do procedimento. Em cada bloco, foram ensinadas, de forma intercalada, respostas de seguir instrução e de tato-intraverbal, mas estão apresentadas em painéis diferentes na Figura 1, pois o número de tentativas para cada repertório variou em função das tentativas com correção e utilização das dicas. P1 foi exposto a 139 tentativas, P2 a 137, P3 a 182 e P4 a 68, visto que todos foram expostos a mais tentativas de ensino de respostas de seguir instrução para alcance de critério. Os participantes alcançaram o critério de aprendizagem (respostas corretas independentes nos dois repertórios em um mesmo bloco) entre cinco e nove blocos de ensino, uma vez que todos os participantes alcançaram, inicialmente, $100 \%$ de acertos para as respostas de tato-intraverbal. Os blocos de ensino foram repetidos, mesmo após alcance de critério, até que os participantes apresentassem 100\% de respostas corretas nos testes dos repertórios não ensinados (respostas de seguir instrução e de tato-intraverbal para a relação espacial oposta à relação ensinada), conforme pode ser visto na Figura 2. Nenhum participante apresentou 100\% de respostas corretas nos testes antes do alcance de critério nos blocos de ensino.

\section{Figura 1}

Desempenho dos participantes ao longo do procedimento de ensino
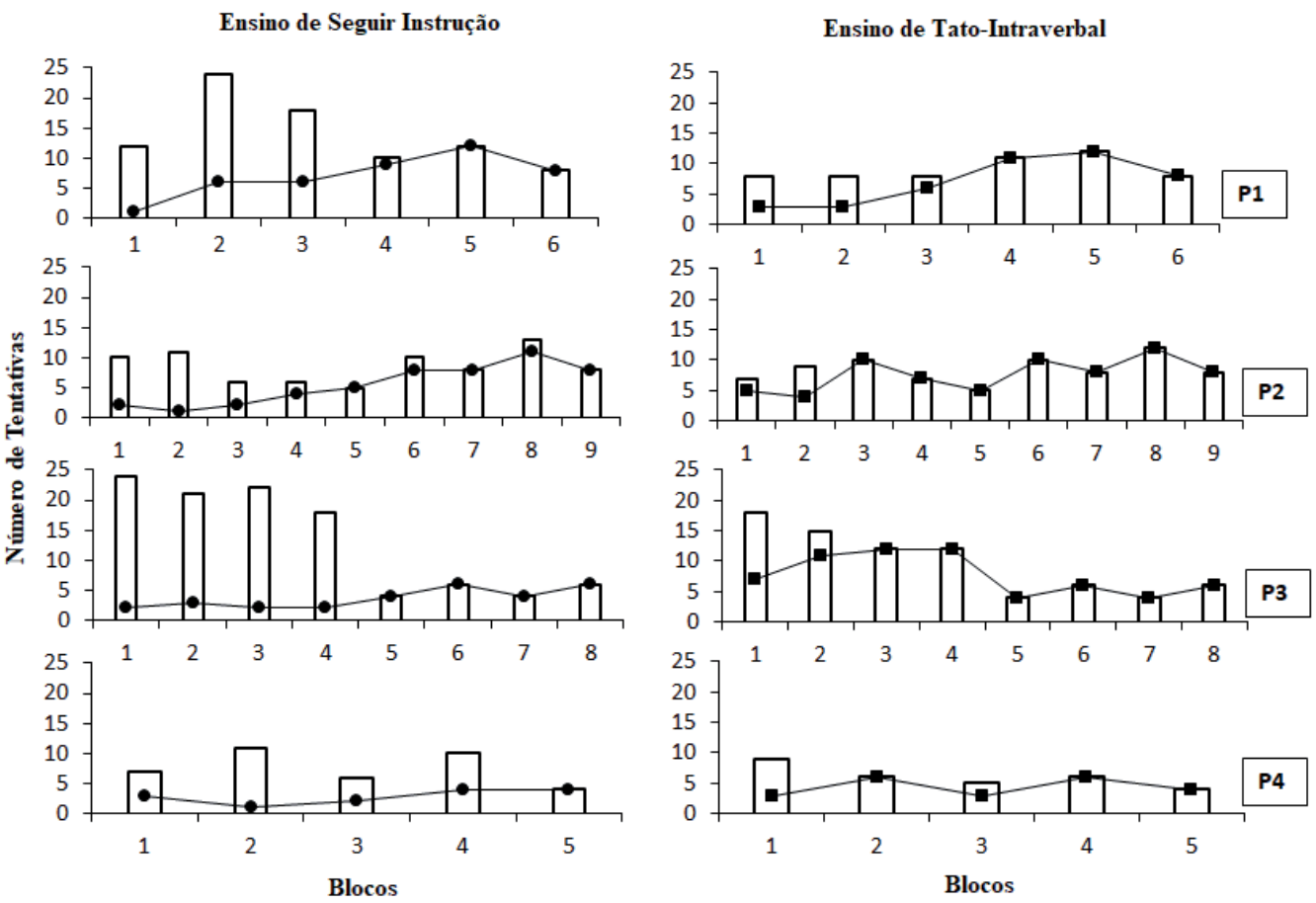

Nota. As barras indicam o número total de tentativas e os pontos indicam o número de respostas corretas. Os painéis à esquerda referem-se ao ensino de seguir instrução e os painéis à direita referem-se ao ensino de tato-intraverbal, que ocorreram em um mesmo bloco, de forma intercalada, pelo ensino com $M E I$.

A Figura 2 a seguir apresenta o número de respostas corretas em cada teste apresentado no início de cada dia de aplicação do procedimento, entre os blocos de ensino. Nota-se que antes da introdução da fase de ensino (dados de linha de base, à esquerda das linhas pontilhadas 
na Figura 2), os participantes não apresentaram uma resposta correta, com exceção de P2 para respostas de seguir instrução nos blocos 1 e 3. Ao final do procedimento, P1, P2 e P3 apresentaram 100\% de respostas corretas e P4 apresentou 100\% e 50\%, respectivamente, para respostas de seguir instrução e tato-intraverbal para a relação espacial oposta à relação diretamente ensinada. Verifica-se também grande variabilidade do número de respostas corretas ao longo do procedimento. Os dados sugerem, ainda, que não há relação entre os desempenhos no procedimento e as características dos participantes, como idade ou alfabetização. Por exemplo, P1, não alfabetizado, alcançou critério em menos blocos que P2, já alfabetizado; da mesma forma, P1, com dez anos, alcançou critério em menos blocos que P3, com 14 anos; e o desempenho de P2, com sete anos, foi semelhante ao P3, com 14 anos.

\section{Figura 2}

Desempenho dos participantes nos testes de repertórios de seguir instrução e de tato-intraverbal ao longo do procedimento, para o lado oposto ao que foi ensinado

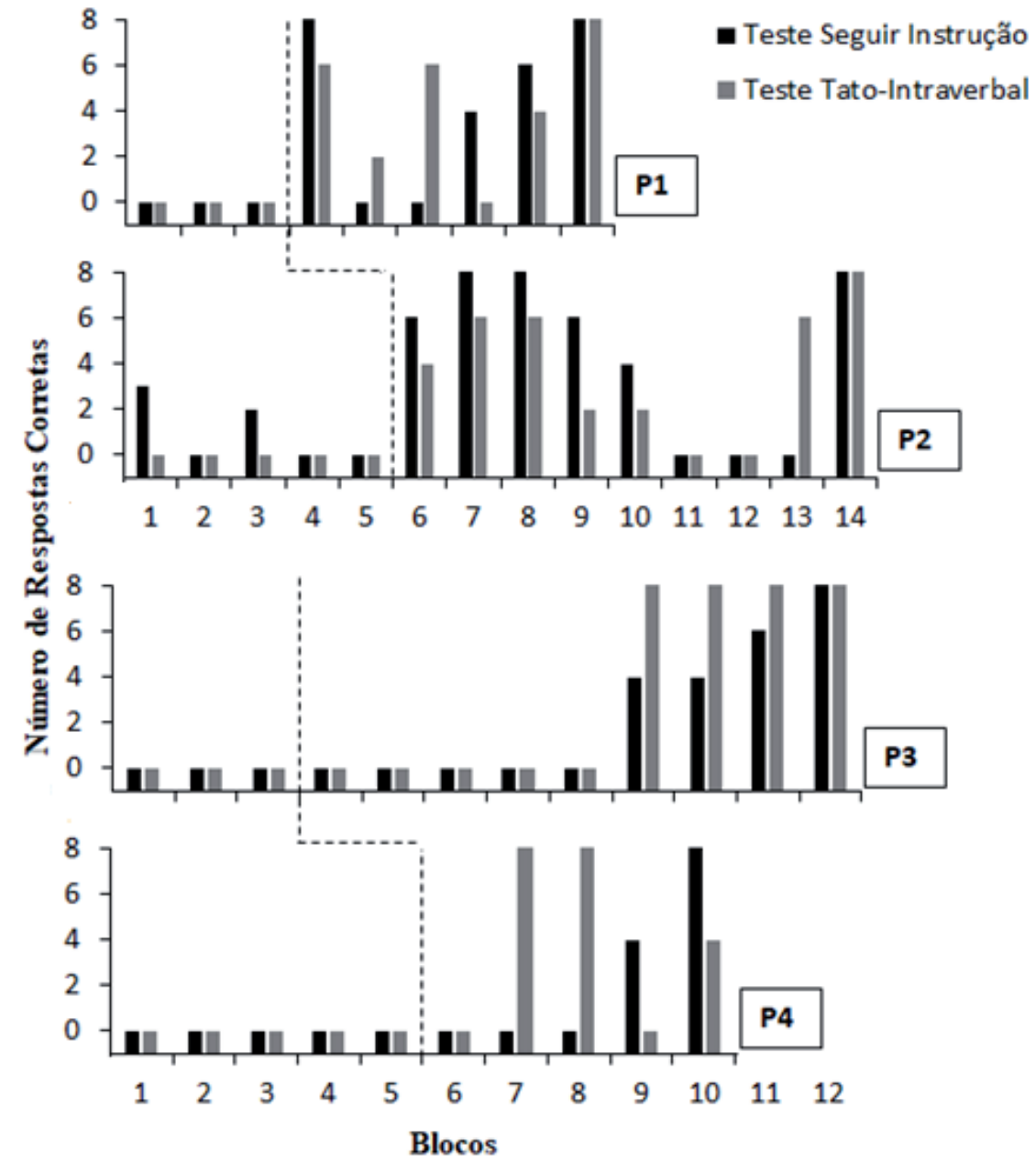

Nota. As linhas pontilhadas representam o delineamento de linha de base múltipla entre participantes e a introdução da fase de ensino. 
A Figura 3 que segue apresenta os desempenhos dos participantes para respostas de seguir instrução e de tato-intraverbal envolvendo objetos (cadeiras, cartóes e carrinhos) para as duas relações espaciais do estudo (esquerda e direita). Em linha de base, P2 e P4 acertaram duas tentativas, em blocos distintos, de seguir instrução para a relação espacial envolvendo o lado direito; nenhum participante acertou tentativas de tato-intraverbal. P1 pegava os dois estímulos ou sentava-se na cadeira do lado incorreto nas tentativas de seguir instrução e repetia a última palavra da pergunta (uma forma de ecolalia) nas tentativas de tato-intraverbal. P2 levantava os dois braços e gritava "Eu" após ouvir a instrução e dizia "Eu”, "Esse" ou a cor do estímulo nas tentativas de tato-intraverbal. P3 pegou os dois estímulos (cartôes e carrinhos) ou deu alguns passos para frente (em direção às cadeiras, mas não se sentou) nas tentativas de seguir instrução e repetia a última palavra da pergunta (possível ecolalia) nas tentativas de tato-intraverbal. P4 emitiu respostas do lado contrário, tanto nas tentativas de seguir instruçáo (por exemplo, pegou o cartão na esquerda quando a instrução especificava direita), quanto de tato-intraverbal (por exemplo, dizia esquerda quando a resposta era direita).

\section{Figura 3}

Percentagens de acertos de cada participante nas sessóes de teste de generalização

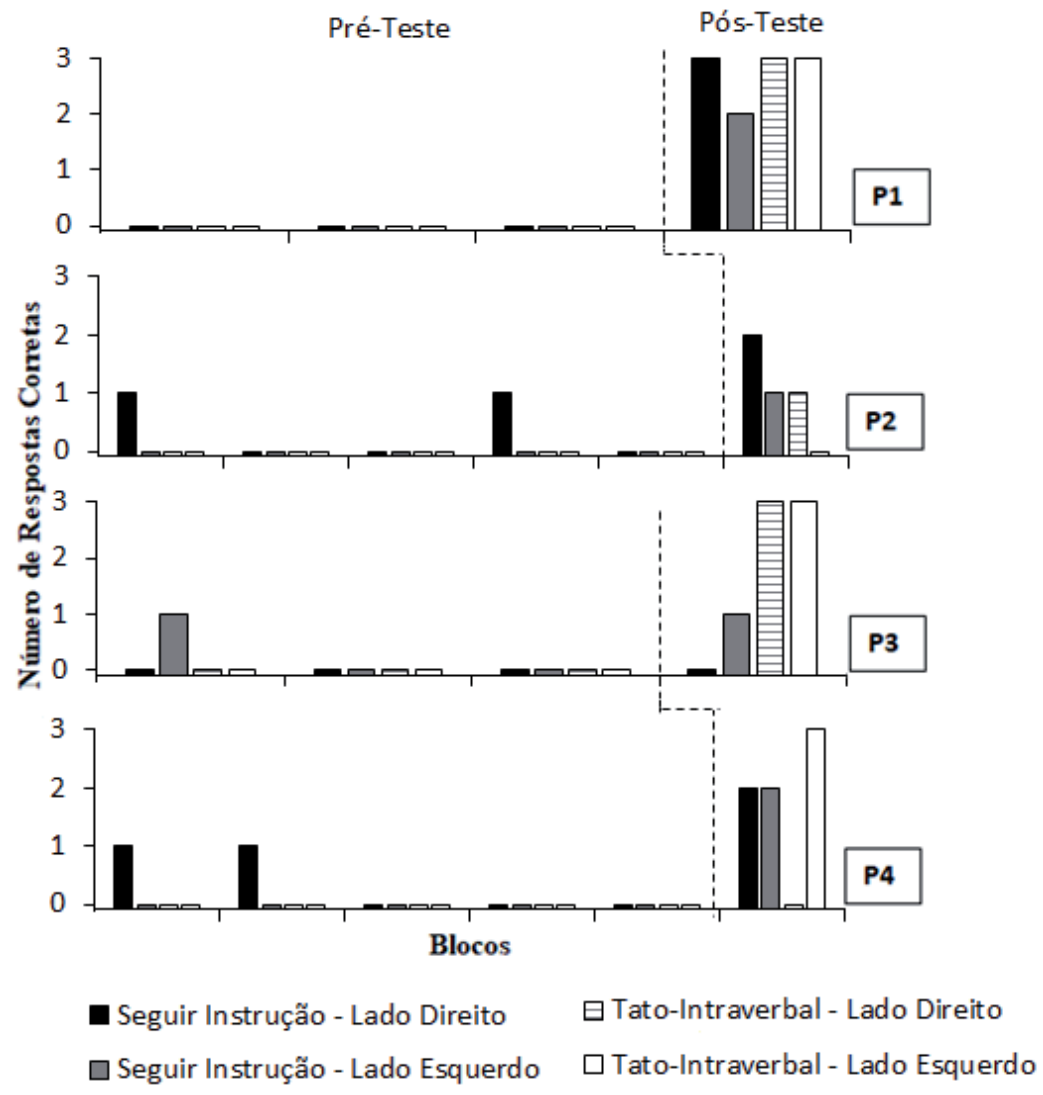


No pós-teste, após a fase de ensino, todos os participantes apresentaram mais respostas corretas em relação aos pré-testes. Entretanto, apenas P1 e P3 acertaram todas as tentativas no pós-teste das respostas de tato-intraverbal. P1 e P3 acertaram mais tentativas de tato-intraverbal e P2 e P4 acertaram mais tentativas de seguir instrução. No total, houve mais respostas corretas de tato-intraverbal (16) do que de seguir instrução (12). Importante notar que todos os participantes emitiram respostas corretas para as duas relaçóes espaciais, mesmo que a fase de ensino tenha utilizado somente uma, de acordo com a distribuiçáo para cada participante. Em relação aos erros no pós-teste de seguir instrução, P1 pegou o carrinho do lado errado, P2 pegou os dois estímulos, P3 pegou os dois estímulos ou pegou o estímulo do lado errado, e P4 também pegou o estímulo do lado errado. Em relação aos erros no pós-teste de tato-intraverbal, P2 falou a cor dos estímulos, e P4 disse o lado errado.

\section{Discussāo}

Os resultados deste estudo sugerem que a exposição ao ensino com $M E I$, envolvendo relaçóes de ouvinte (seguir instruçáo) e de falante (tato-intraverbal) para uma das relaçóes espaciais (por exemplo, esquerda), foi suficiente para a emergência dessas relaçóes abranger a outra relação espacial (por exemplo, direita), conforme resultados dos testes ao longo do procedimento, e outros estímulos do ambiente (como partes do corpo e objetos), de acordo com os resultados no pós-teste de generalização.

Fiorile e Greer (2007), Kobari-Wright e Miguel (2014) e Elias e Arantes (2019) propóem que a nomeação (relação bidirecional entre comportamentos de ouvinte e de falante, segundo Horne \& Lowe - 1996) é o operante fundamental e básico para o desenvolvimento da linguagem. Portanto, neste estudo, a opção experimental de ensinar respostas de ouvinte (seguir instrução) e de falante (tato-intraverbal), de forma intercalada, parece ter sido relevante para produzir os resultados encontrados. Estudos futuros poderiam ensinar somente uma das relaçóes (de seguir instrução ou de tato-intraverbal) para apenas uma das relaçóes espaciais (esquerda ou direita) e testar a emergência das outras relaçóes possíveis, identificando se é realmente necessário ensinar as duas relaçóes envolvidas na nomeação bidirecional. Outrossim, conforme sugerem Greer et al. (2007), o ensino com MEI é um recurso promissor para o desenvolvimento da nomeação e para programas de ensino de linguagem.

Esses resultados promissores podem ter sido função do ensino com $M E I$ e, também, do uso de dois estímulos opostos (esquerda e direita) e dos testes repetidos que foram aplicados ao longo do procedimento. Nesse sentido, pode-se inferir que houve uma possível aprendizagem por exclusão (Wilkinson et al., 2000); dito de outro modo, se o participante já aprendeu a levantar o braço direito na presença da instrução "Levante o braço direito", ao ouvir "Levante o braço esquerdo", por exclusão, ele levanta o outro braço. Entretanto, os resultados nos testes de generalização, em que foram apresentados estímulos que não foram utilizados durante a fase de ensino, sugerem que os participantes aprenderam a responder sob controle das relaçóes espaciais.

Os resultados dos pré-testes de generalização sugerem que alguns participantes respondiam sob controle restrito de estímulos ou sob controle de parte dos elementos que compunham a instrução ou a pergunta (Dube et al., 2010; Lovaas et al., 1971), por exemplo, P1 e P3 pegavam os dois estímulos e repetiam a última palavra da pergunta. Na primeira situação, ao 
ouvir a instrução "Pegue o carrinho da direita", eles podem ter ficado sob controle somente da parte inicial da instrução "Pegue o carrinho"; na outra situação, ao ouvir "De que lado está esse carrinho?”, eles podem ter ficado sob controle da última palavra falada pela experimentadora.

O pós-teste de generalização sugere que os participantes passaram a responder sob controle de todos os elementos das instruçóes e das perguntas, pois erros como pegar os dois estímulos diminuíram e repetir a última palavra (ecolalia) não aconteceu nenhuma das vezes. Alguns estudos (Ahearn et al., 2007; Guzinski et al., 2012) têm demonstrado que estereotipia vocal e ecolalia podem ser reduzidas como função do aprendizado de respostas vocais apropriadas.

$\mathrm{Na}$ fase de ensino, os participantes foram expostos ao $M E I$ para respostas de seguir instrução, intercaladas com respostas de tato-intraverbal para uma mesma relação espacial, até atingirem o critério de $100 \%$ de respostas corretas para os dois repertórios. O número de blocos para atingir esse critério variou de cinco a nove blocos e o número de tentativas variou de 68 a 182. Nos pós-testes de generalização, o número total de respostas corretas variou de quatro a 11. Esses dados evidenciam a grande variabilidade comportamental e de aprendizagem encontrada no TEA $(A P A, 2013)$, mesmo que o desempenho inicial para as respostas de interesse do estudo fosse bastante semelhante, conforme identificado nos testes em linha de base.

\section{CONSIDERAÇÓES FINAIS}

De forma geral, pode-se dizer que o procedimento proposto neste estudo foi eficaz e eficiente, pois gerou a emergência de respostas de seguir instruçóes e de tato-intraverbal não ensinadas diretamente e o alcance de critério de aprendizagem, na fase de ensino, deu-se em poucos blocos. Uma possível limitação deste estudo foi o uso de somente duas relaçóes espaciais (esquerda e direita), o que possibilitou respostas por exclusão e a aplicação de um único pós-teste de generalização. A replicação com mais participantes é fortemente aconselhável para verificar a extensão dos dados encontrados e a participação de indivíduos dentro do TEA com outras características e outros repertórios verbais de entrada.

\section{REFERÊNCIAS}

Ahearn, W. H., Clark, K. M., Macdonald, R. P., \& Chung, B. (2007). Assessing and treating vocal stereotypy in children with autism. Journal of Applied Behavior Analysis, 40 (2), 263-275. https:// doi.org/10.1901/jaba.2007.30-06

American Psychiatric Association. (2013). Diagnostic and Statistical Manual of Mental Disorders: DSM-V. APA.

Carr, J. E., Nicolson, A. C., \& Higbee, T. S. (2000). Evaluation of a brief multiple-stimulus preference assessment in a naturalistic context. Journal of Applied Behavior Analysis, 33(3), 353-357. https:// doi.org/10.1901/jaba.2000.33-353

Contreras, B. P., Cooper, A. J., \& Kahng, S. (2020). Recent research on the relative efficiency of speaker and listener instruction for children with autism spectrum disorder. Journal of Applied Behavior Analysis, 53(1), 584-589. https://doi.org/10.1002/jaba.543 
Cooper, J. O., Heron, T. E., \& Heward, W. L. (2007). Análise de comportamento aplicada. Merrill Prentice Hall.

Cozby, P. C. (2014). Métodos de pesquisa em ciência do comportamento. Atlas.

Dube, W. V., Dickson, C. A., Balsamo, L. M., O’Donnel, K. L., Tomanari, G. Y., Farren, K. M., Wheeler, E. E., \& Mcilvane, W. J. (2010). Observing behavior and atypically restricted stimulus control. Journal of the Experimental Analysis of Behavior, 94(3), 297-313. https://doi.org/10.1901/ jeab.2010.94-297

Elias, N. C., \& Arantes, A. (2019). Teorias comportamentais sobre a etiologia do autismo e uma nova proposta. In J. C. Luzia, J. Gamba, N. Kienen, \& S. R. de S. A. Gil (Eds.), Psicologia e análise do comportamento: pesquisa e intervenção ( $\left.1^{\mathrm{a}} \mathrm{ed} ., \mathrm{pp} .134-146\right)$. Universidade Estadual de Londrina.

Fiorile, C. A., \& Greer, R. D. (2007). The induction of naming in children with no prior tact responses as a function of multiple exemplar histories of instruction. The Analysis of Verbal Behavior, 23(1), 71-87. https://doi.org/10.1007/bf03393048

Gast, D. L., \& Ledford, J. R. (2014). Single case research methodology: Applications in special education and behavior-al sciences. Routledge.

Greer, R. D., Stolfi, L., \& Pistoljevic, N. (2007). Emergence of naming in preschoolers: A comparison of multiple and single exemplar instruction. European Journal of Behavior Analysis, 8(2), 109-131. https://doi.org/10.1080/15021149.2007.11434278

Guzinski, E. M., Cihon, T. M., \& Eshleman, J. (2012). The effects of tact training on stereotypic vocalizations in children with autism. The Analysis of Verbal Behavior, 28(1), 101-110. https://doi. org/10.1007/BF03393110

Haebig, E., \& Sterling, A. (2017). Investigating the receptive-expressive vocabulary profile in children with idiopathic ASD and comorbid ASD and fragile $\mathrm{x}$ syndrome. Journal of Autism and Developmental Disorders, 47(2), 260-274. https://doi.org/10.1007/s10803-016-2921-3

Horne, P., \& Lowe, C. F. (1996). On the origins of naming and other symbolic behavior. Journal of the Experimental Analysis of Behavior, 65, 185-241. https://doi.org/10.1901/jeab.1996.65-185

Kazdin, A. E. (1982). Single-case research designs: Methods for clinical and applied settings. Oxford University Press.

Kobari-Wright, V. V., \& Miguel, C. F. (2014). The effects of listener training on the emergence of categorization and speaker behavior in children with autism. Journal of Applied Behavior Analysis, 47(2), 431-436. https://doi.org/10.1002/jaba.115

Lovaas, O. I., Schreibman, L., Koegel, R. L., \& Rehm, R. (1971). Selective responding by autistic children to multiple sensory input. Journal of Abnormal Psychology, 77(3), 211-222. https://doi. org/10.1037/h0031015

Petursdottir, A. I., \& Carr, J. E. (2011). A review of recommendations for sequencing receptive and expressive language instruction. Journal of Applied Behavior Analysis, 44(4), 859-876. https://doi. org/10.1901/jaba.2011.44-859

Skinner, B. F. (1957). Verbal Behavior. Applenton-Century-Crofts. 
SILVA, E.C. \& ELIAS, N.C.

Sprinkle, E. C., \& Miguel, C. F. (2012). The effects of listener and speaker training on emergent relations in children with autism. The Analysis of Verbal Behavior, 28(1), 111-117. https://doi.org/10.1007/ bf03393111

Wilkinson, K. M., De Souza, D. G., \& Mcllvane, W. J. (2000). As origens da exclusão. Temas em Psicologia, 8(2), 195-203.

Recebido em: 01/11/2020

Reformulado em: 07/05/2021

Aprovado em: 10/05/2021 